\title{
Organometallic approach for platinum and palladium doping of tin and tin oxide nanoparticles: structural characterisation and gas sensor investigations
}

\author{
Laurent Erades, ${ }^{a}$ Didier Grandjean, ${ }^{b}$ Céline Nayral, ${ }^{a}$ Katerina Soulantica, ${ }^{a}$ \\ Bruno Chaudret, ${ }^{a}$ Philippe Menini, ${ }^{c}$ Frederic Parret $^{c}$ and André Maisonnat ${ }^{* a}$
}

Received (in Montpellier, France) 9th January 2006, Accepted 7th April 2006

First published as an Advance Article on the web 16th May 2006

DOI: $10.1039 / b 600197$ a

Platinum and palladium surface doped tin nanoparticles have been obtained by decomposition of $\left[\mathrm{Pt}_{2}(\mathrm{dba})_{3}\right]$ and $\left[\mathrm{Pd}(\mathrm{dba})_{2}\right]$ organometallic precursors, respectively, in a colloidal suspension of tin/ tin oxide core-shell nanoparticles of uniform size $(\approx 13 \mathrm{~nm})$, in anisole under 1 bar of carbon monoxide at room temperature. The particles can be isolated as pure solids and present effective doping ratios $[\mathrm{Pt}] /[\mathrm{Sn}]$ and $[\mathrm{Pd}] /[\mathrm{Sn}]$ of 2.5 and $3.1 \%$, respectively. These nanomaterials have been characterized by means of transmission electron and high-resolution transmission electron microscopies (TEM and HRTEM), Energy Dispersive X-ray spectroscopy (EDX), photoelectron spectroscopy (XPS) and X-ray absorption spectroscopy (EXAFS and XANES). The TEM micrographs show spherical nanoparticles whose size and size distribution are essentially similar to those of the initial $\mathrm{Sn} / \mathrm{SnO}_{x}$ material. HRTEM, EDX, XPS and X-ray absorption spectroscopy (XAS) studies at the $\mathrm{Pd}$ and/or Sn-K edge show the conservation of the composite nature of the particles that consist of a tin( 0$)$ core covered with a layer of tin oxides on which the doping element is deposited under the form of crystalline metallic platelets of size near $2 \mathrm{~nm}$. The thermal oxidation of these Pt- or Pd-doped tin materials yields nanoparticles of crystallized $\mathrm{SnO}_{2}$ covered with crystallites of Pt or Pd oxides, as demonstrated by XRD, XPS and XAS experiments, without coalescence or size change. In the oxidised Pd-doped material, EXAFS analysis combined with HRTEM, point towards the formation of two main Pd disordered oxide phases: a rather pure oxopalladate $\mathrm{Pd}_{3.5} \mathrm{O}_{4}$-type phase at the surface of the particle and a mixed $\mathrm{Pd} / \mathrm{Sn}$ phase having a $\mathrm{PdO}$ structure-type at the interface $\mathrm{Pd}$ oxide/Sn oxide. The thermal oxidation process can be easily achieved onto the silicon platform of a micro-machined device after integration of the Pt- or Pd-doped $\mathrm{Sn} / \mathrm{SnO}_{x}$ colloidal suspension by drop deposition. The first electrical measurements indicate remarkable behaviours of the as-obtained microsensors when exposed to traces of carbon monoxide. In addition to the expected large increase of sensitivity of the doped relatively to the undoped sensitive layer measured in humid atmosphere, a surprising and unprecedented inversion of sensitivity from undoped to Pt- and Pd-doped sensors has been observed in dry atmosphere.

\section{Introduction}

Metal oxides are widely employed as sensitive element in gas sensors $^{1-4}$ and commercial devices produced by a typical ceramic manufacturing process have been available for a long time. ${ }^{5}$ Such devices are able to detect low concentration of flammable or toxic gases at a ppm level but their lack of selectivity and long term stability remains their weak points,

\footnotetext{
${ }^{a}$ Laboratoire de Chimie de Coordination du CNRS, UPR 8241, 205 route de Narbonne, F-31077 Toulouse Cedex 04, France. E-mail: andre.maisonnat@lcc-toulouse.fr; Fax: +33 5615530 03; Tel: +33 561333189

${ }^{b}$ Inorganic Chemistry and Catalysis, Department of Chemistry, Utrecht University - Sorbonnelaan 16, 3584 CA Utrecht, The Netherlands

${ }^{c}$ Laboratoire d'Analyse et d'Architecture des Systèmes du CNRS, UPR 8001, 7 avenue du Colonel Roche, F-31077 Toulouse Cedex 04, France
}

and improving the cross sensitivities between gases such as $\mathrm{CO}, \mathrm{H}_{2}$, hydrocarbons and $\mathrm{NO}_{2}$ remains a major problem.

Even though modulations of the sensor response to a given gas in a mixture can be achieved through the optimization of the working temperature of the sensitive layer, ${ }^{6}$ of the operating mode and the signal processing, ${ }^{7-9}$ an accurate control of the morphology of the sensing materials, in the nanometre range, is well known as an inescapable prerequisite for improvement of sensor performances. ${ }^{7,10-13}$ If the addition of small amounts of a noble metal has been shown to improve the detection of various gases, ${ }^{10,14-21}$ sensitivity and selectivity again depend on the morphology of the as-obtained doped material, both in terms of distribution and crystal size of the added noble metals. ${ }^{22-25}$

In previous studies, we have evidenced the interest of organometallic complexes for the preparation of metal nanoparticles of controlled size, shape and organization. ${ }^{26-33} \mathrm{We}$ 
have shown that this methodology can be extended to the synthesis of nanoparticles of metal oxides with a precise control of morphology. Thermolysis of $\left[\mathrm{ZnCy}_{2}\right](\mathrm{Cy}=$ $\left.\mathrm{C}_{6} \mathrm{H}_{11}\right)$ or $\left[\left\{\mathrm{Sn}\left(\mathrm{NMe}_{2}\right)_{2}\right\}_{2}\right]$ in anisole or methanolysis of InCp $\left(\mathrm{Cp}=\eta^{5}-\mathrm{C}_{5} \mathrm{H}_{5}\right)$, in toluene indeed lead to the formation of zinc, tin or indium nanoparticles of low size dispersity ${ }^{34-37}$ which can be, in a second step, oxidized into well crystallized nanoparticles of the corresponding oxides, without coalescence. We recently reported a direct organometallic route to prepare $\mathrm{ZnO}$ colloidal solutions containing nanoparticles of controlled size and shape. ${ }^{38}$

We have also shown that dibenzylideneacetone derivatives of palladium and platinum can be used as precursors to yield metal nanoparticles of uniform sizes in the range $1.2-2.5 \mathrm{~nm}$ by submitting solutions of these compounds to $\mathrm{CO}$ or $\mathrm{H}_{2}$ in the presence of a stabilizing agent as such as polymers or organic ligands. ${ }^{39-41} \mathrm{We}$ demonstrate in this paper that these $\mathrm{Pd}$ and Pt organometallic complexes can effectively be used as precursors to surface doping tin nanoparticles through very mild conditions and with an accurate control of morphology. The reaction with $\mathrm{CO}$ of $\left[\mathrm{Pt}_{2}(\mathrm{dba})_{3}\right]$ or $\left[\mathrm{Pd}(\mathrm{dba})_{3}\right]$ in anisole containing tin nanoparticles indeed leads to the formation of tin/platinum or tin/palladium nanoparticles. Partial aspects of this work, including essentially X-ray absorption experiments of the tin/palladium particles, have been previously reported. ${ }^{42}$ We describe here the full characterization of the tin/platinum and tin/palladium particles by elemental analyses, electron microscopy (TEM and HRTEM), energy dispersion X-ray analysis (EDX) and X-ray photoelectron spectroscopy (XPS). The oxidation of these materials to yield tin dioxide nanoparticles covered with platinum or palladium oxides of similar spherical morphology is also described together with their full characterization by TEM and HRTEM, XPS and X-ray absorption spectroscopy (EXAFS and XANES). Finally, the implementation of the tin/palladium and tin/platinum nanocomposites as a sensitive layer on the silicon platform of a gas microsensor as well as their electrical properties under carbon monoxide is presented.

\section{Experimental}

\section{Materials and reagents}

All compounds used in this work were sensitive to oxygen and moisture and were manipulated either in a standard vacuum line or in argon atmosphere by using a MBraun Inert Gas System. Preparation of the platinum and palladium precursors, $\left(\left[\mathrm{Pt}_{2}(\mathrm{dba})_{3}\right]\right.$ and $\left[\mathrm{Pd}(\mathrm{dba})_{2}\right]$, respectively) follows the routes described earlier. ${ }^{43}$ Anisole was purchased from Aldrich and its water content was checked by Karl-Fisher coulometric titration using a Metrohm equipment.

Preparation of the $\left[\mathrm{Sn} / \mathrm{SnO}_{x}\right]$ colloidal suspension. Preparation of the tin colloid follows the route described previously. $^{35,44}$ The precursor $\left[\mathrm{Sn}\left(\mathrm{NMe}_{2}\right)_{2}\right]_{2} \quad(174 \mathrm{mg}, \quad 0.42$ mmol; $0.84 \times 10^{-3}$ eq. $\mathrm{Sn}$ ), in anisole (degassed under vacuum at liquid nitrogen temperature; $15 \mathrm{~mL}$ ) containing traces of water $\left(0.4 \mathrm{mg} \mathrm{mL}^{-1}\right.$ of anisole; $\left.0.33 \mathrm{mmol} ;\left[\mathrm{H}_{2} \mathrm{O}\right] /[\mathrm{Sn}]=0.4\right)$ were heated at $135{ }^{\circ} \mathrm{C}$ under magnetic stirring in a Fischer-Porter bottle. The initial yellow solution darkened within $10 \mathrm{~min}$ and a black solid progressively precipitated. After $3 \mathrm{~h}$, the solution was removed by filtration, and the black precipitate was washed with anisole $(3 \times 10 \mathrm{~mL})$. The black solid was then re-dispersed in $15 \mathrm{~mL}$ of degassed anisole and the Fischer-Porter bottle was then pressurized to 3 bar of dihydrogen. After stirring for $3 \mathrm{~h}$, the resulting suspension was sampled for TEM analysis: nanoparticles, size 7-20 nm (Gaussian fit, mean size: 13.2(2.2) nm).

Decomposition of $\left[\mathrm{Pt}_{\mathbf{2}}(\mathrm{dba})_{3}\right]$ in $\left[\mathrm{Sn} / \mathrm{SnO}_{x}\right]$ colloidal suspension. To $7.5 \mathrm{~mL}$ of the suspension of $\left[\mathrm{Sn} / \mathrm{SnO} \mathrm{O}_{x}\right]$ in anisole $\left(0.21 \times 10^{-3}\right.$ eq. $\left.\mathrm{Sn}\right)$ was added the platinum precursor $(1 \mathrm{~mL}$ of a solution containing $46 \mathrm{mg}$ of $\left[\mathrm{Pt}_{2}(\mathrm{dba})_{3}\right]$ in $10 \mathrm{~mL}$ of anisole; $0.0042 \mathrm{mmol} ;[\mathrm{Pt}] /[\mathrm{Sn}]=4 \%$ ). The mixture was exposed to 1 bar of $\mathrm{CO}$ in a Fisher-Porter bottle. After 20 min of stirring, the Fisher-Porter bottle was evacuated and the resulting black suspension was sampled for TEM, HRTEM, EDX and XPS experiments. The supernatant solution was then removed by filtration from the remaining suspension and the precipitate was washed with anisole $(3 \times 15 \mathrm{~mL})$ and dried under vacuum. Elemental analysis (\%): Sn 79.23; Pt 3.23; [Pt]/ $[\mathrm{Sn}]=2.5 \%$; doping yield: $62.5 \%$; TEM analysis: nanoparticles, size 7-19 nm (Gaussian fit, mean size: 13.4(1.7) nm).

Decomposition of $\left[\mathrm{Pd}(\mathrm{dba})_{2}\right]$ in $\left[\mathrm{Sn} / \mathrm{SnO}_{x}\right]$ colloidal suspension. Similarly, to a colloidal suspension of $\left[\mathrm{Sn} / \mathrm{SnO}_{x}\right]$ in anisole $\left(0.42 \times 10^{-3}\right.$ eq. $\left.\mathrm{Sn} ; 15 \mathrm{~mL}\right)$ was added the palladium precursor $(4.8 \mathrm{~mL}$ of a solution containing $20.0 \mathrm{mg}$ of $\left[\mathrm{Pd}(\mathrm{dba})_{2}\right]$ in $10 \mathrm{~mL}$ of anisole; $0.0167 \mathrm{mmol} ;[\mathrm{Pd}] /[\mathrm{Sn}]=$ $4 \%$ ). After exposition to 1 bar of CO during $20 \mathrm{~min}$, depressurization, sampling for TEM, HRTEM, EDX, XPS and XAS experiments, decantation filtration and drying under vacuum, a black powder was obtained. Elemental analysis (\%): Sn 73.72; Pd 2.06; [Pd]/[Sn] = 3.09\%; doping yield: 77\%; TEM analysis: nanoparticles, size 7-19 nm (Gaussian fit, mean size: 13.2(1.7) $\mathrm{nm})$.

Thermal oxidation of tin/platinum and tin/palladium products. The black solids resulting from the decomposition of $\left[\mathrm{Pt}_{2}(\mathrm{dba})_{3}\right]$ and $\left[\mathrm{Pd}(\mathrm{dba})_{2}\right]$ in $\left[\mathrm{Sn} / \mathrm{SnO}_{x}\right]$ colloidal suspensions were heat-treated in air in an oven for a period of $135 \mathrm{~min}$ at temperatures ranging from 50 to $525^{\circ} \mathrm{C}$ according to the optimized multistep process already used for the oxidation of $\left[\mathrm{Sn} / \mathrm{SnO}_{x}\right]$ nanoparticles. ${ }^{35}$

\section{Experimental techniques}

Electron microscopy. Samples for TEM and HRTEM studies were prepared in a glove-box by slow evaporation of a drop of suitably diluted colloidal suspensions deposited on holey carbon-covered grids. The TEM experiments were performed at the "Service Commun de Microscopies de l'Universite Paul Sabatier" on a JEOL JEM 200CXT-T electron microscope working at $200 \mathrm{kV}$ and a Philips CM12 electron microscope working at $120 \mathrm{kV}$ while the high resolution images were obtained with a JEOL JEM 2010 electron microscope operating at $200 \mathrm{kV}$. The size distribution of the particles was determined from enlarged photographs by measuring a minimum of 200 particles for each sample. 
X-Ray photoelectron spectroscopy. Samples for XPS studies were prepared in a glove-box by slow evaporation of a nanoparticle suspension deposited on a $1 \mathrm{~cm}^{2}$ silicon support. The spectra were recorded on a VG ESCALAB MKII spectrometer using an $\mathrm{Mg}$ - $\mathrm{K} \alpha \mathrm{X}$-ray source.

X-Ray absorption spectroscopy. X-ray absorption data were collected on beamline X1 (Hasylab, DESY, Hamburg, Germany), operating under beam conditions of $4.4 \mathrm{GeV}, 150 \mathrm{~mA}$ using a Si (311) double-crystal monochromator. The monochromator was detuned on its rocking curve to approximately $60 \%$ of the maximum transmitted X-ray intensity to reduce the harmonic content of the beam at a minimum level. Ionisation chambers were filled with standard $\mathrm{N}_{2}-\mathrm{Ar}$ mixtures. Appropriate amounts of sample were finely ground with boron nitride and pressed into a self-supporting wafer producing a suitable edge jump. XAS signals at the $\mathrm{Pd} \mathrm{K}$ edge $(24350.3 \mathrm{eV})$ were measured in transmission mode at $80 \mathrm{~K}$ by cooling the samples with liquid-nitrogen. PdO powder (Aldrich 99.999\%) was used as reference sample.

Data reduction of experimental X-ray absorption spectra was performed using the program EXBROOK. ${ }^{45}$

Pre-edge background subtraction and normalisation was carried out by fitting a linear polynomial to the pre-edge region and cubic splines to the post-edge region of the absorption spectrum. EXAFS refinements were performed with the EXCURV98 package. ${ }^{45}$

Phase shifts and backscattering factors were calculated ab initio using Hedin-Lundqvist potentials. Refinements were carried out using $k^{3}$ weighting in the range $2.5-15 \AA^{-1}$ for the reference compounds and $k^{2}$ in the range $3.0-12.6 \AA^{-1}$ for the $\mathrm{Pd}$ doped $\mathrm{SnO}_{2}$ nanomaterial. In order to improve the quality of the signal for a better quantitative analysis and to reduce the number of fitting parameters, the data for all the samples (except for bulk Pd) were refined using Fourier filtering techniques. Fourier transform (FT's) peaks were isolated with a Gaussian window (1.0-4.9 $\AA$ ) and the contribution of this group of shells was extracted by inverse transformation.

\section{Implementation of colloidal suspensions of platinum and palladium doped tin/tin oxide nanoparticles on silicon platform and conductivity measurements under carbon monoxide}

A drop of the doped colloidal tin/tin oxide suspension in anisole is deposited on the heating element and electrical contacts of a silicon platform of a chemical sensor device integrating all structures that are needed to receive and make operational a sensing layer (heater, metal interconnects, membrane, insulating layer...) according to a procedure previously described. ${ }^{46,47}$ The integrated microheater is used to in situ oxidize the doped tin/tin oxide colloid layer at a temperature close to $500{ }^{\circ} \mathrm{C}$ according to the multistep process previously described, ${ }^{35,46}$ to form fully oxidized platinum and palladium doped tin dioxide structures. The sensor heating was controlled by a constant-voltage power supply. The conductivity measurements on the sensitive layers were carried out under controlled atmosphere in a flow chamber at a flow rate of $1 \mathrm{~L}$ $\min ^{-1}$, a temperature of $21{ }^{\circ} \mathrm{C}$ and a variable relative humidity rate on a test bench using interface hardware. Humidity concentration was controlled by mixing appropriate fractions of dry and saturated synthetic air. The data acquisition was carried out through Labview software (National Instruments).

\section{Results and discussion}

\section{Synthesis and characterization of $\left[\mathrm{Sn} / \mathrm{SnO}_{x} / \mathrm{Pt}\right]$ nanoparticles}

We recently demonstrated that the reaction of $\left[\mathrm{Pt}_{2}(\mathrm{dba})_{3}\right]$ with carbon monoxide in THF leads to the formation of well crystallized platinum nanoparticles of uniform size centred near $1.2 \mathrm{~nm}^{41}$ which can be easily functionalized through coordination of various ligands at their surface. This organometallic complex then appears as a convenient potential precursor for the doping of tin nanoparticles, and we observed indeed that $\left[\mathrm{Pt}_{2}(\mathrm{dba})_{3}\right]$ also decomposed in the presence of colloidal tin/tin oxide nanoparticles suspended in anisole, when exposed to $1 \mathrm{~atm}$ of carbon monoxide.

Elemental analysis of the black product isolated after the reaction indicates that $62.5 \%$ of the platinum initially introduced in the medium has been incorporated into the tin/tin oxide material. Transmission electron microscopy (TEM) observation and energy dispersive X-ray spectroscopy (EDX) of this black product revealed the presence of spherical nanoparticles of uniform size centred around $13.4 \mathrm{~nm}$, as in the starting $\left[\mathrm{Sn} / \mathrm{SnO}_{x}\right]$ colloid (13.2 (2.2) nm) (Fig. 1(a) and (b)), as well as the homogeneous distribution, at a macroscopic scale, of both $\mathrm{Sn}$ and $\mathrm{Pt}$ elements in the sample, the $[\mathrm{Pt}] /[\mathrm{Sn}]$ mean atom ratios determined from different samples of several tenths of particles, i.e. around $2.3 \%$ for each EDX measurement, being in good agreement with the composition obtained from elemental analysis, within the limits of instrument sensitivity.

Although the core-shell morphology observed in the starting tin colloidal material ${ }^{34,35}$ is not apparent on the HRTEM image of the doped tin/tin oxide particles (Fig. 2), this morphology that would result from the deposition of the added platinum on the tin oxide surface of the starting material as shown on Scheme 1, is consistent with the results of the surface analysis by X-ray photo-emission spectroscopy (XPS).

The $\mathrm{Sn} 3 \mathrm{~d}_{5 / 2}$ peak indeed splits into two components with binding energies of 484.7 and $486.4 \mathrm{eV}$ indicative of both tin oxides and $\operatorname{tin}(0)$ (Fig. 3). A Pt $4 \mathrm{f}_{7 / 2}$ peak appears at $69.5 \mathrm{eV}$ and corresponds clearly to zero-valent platinum. ${ }^{48}$ Moreover, after a 1 min argon bombardment of the sample, the tin(0) component located at $484.7 \mathrm{eV}$ increases considerably relatively to the tin oxide component at $486.4 \mathrm{eV}$, whereas the atom ratio $[\mathrm{Pt}] /[\mathrm{Sn}]$ decreases from 2.3 to $1.4 \%$.

\section{Synthesis and characterization of $\left[\mathrm{Sn} / \mathrm{SnO}_{x} / \mathrm{Pd}\right]$ nanoparticles}

Similarly, the decomposition under $\mathrm{CO}$ atmosphere of $\mathrm{Pd}(\mathrm{dba})_{2}$ in the presence of colloidal $\left[\mathrm{Sn} / \mathrm{SnO} \mathrm{O}_{x}\right]$ suspended in anisole yields $\left[\mathrm{Sn} / \mathrm{SnO}_{x} / \mathrm{Pd}\right]$ material as a black solid. The elemental analysis of this solid indicates that $77 \%$ of the

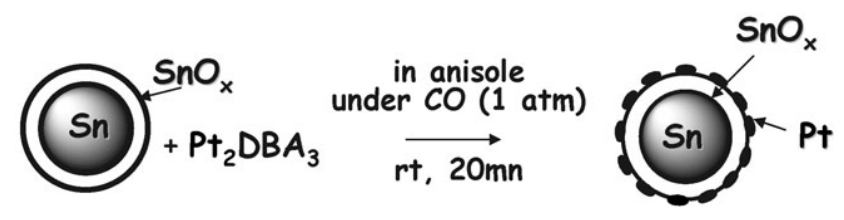

Scheme 1 

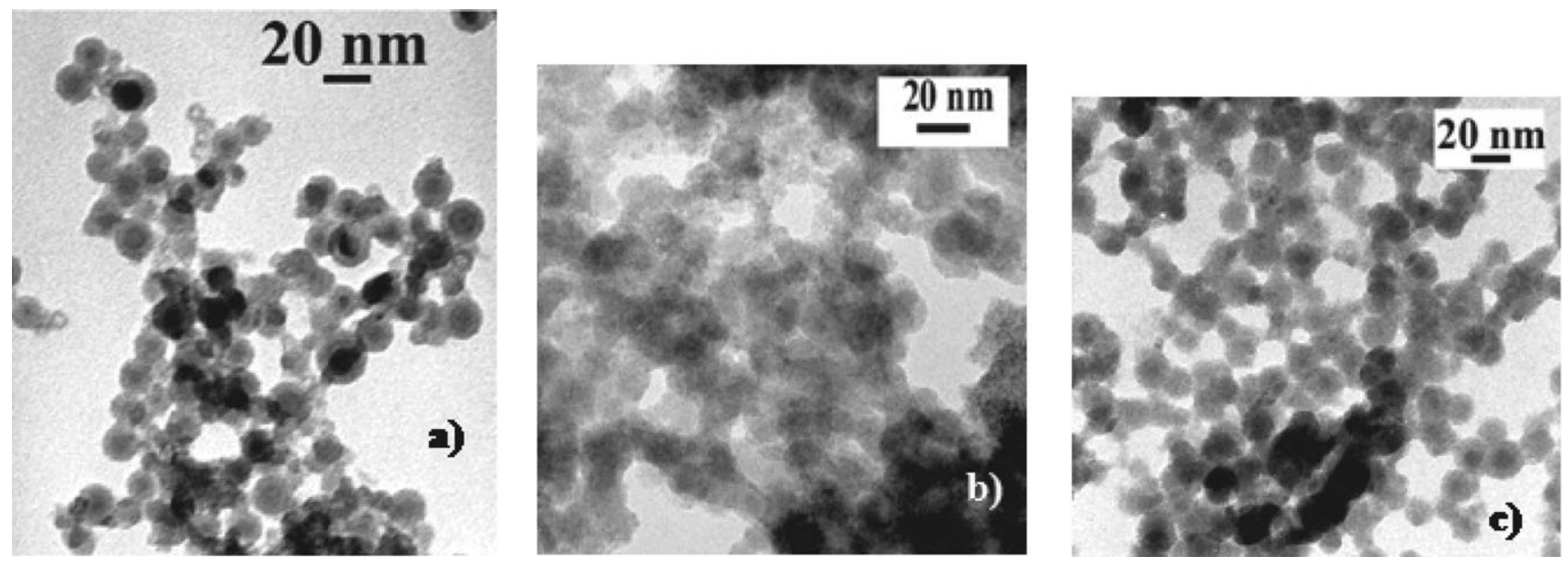

Fig. 1 TEM image of tin/tin oxide nanoparticles (a) before doping and after (b) platinum- or (c) palladium-doping.

palladium initially introduced in the starting suspension has been incorporated into the tin/tin oxide colloid. TEM observation points out again a similar spherical morphology with a similar mean diameter as in the tin/tin oxide material (Fig. 1(c)). On the HRTEM images of Fig. 4, small crystallites at the surface of the particles can be observed. Although the exact nature of the phase(s) forming these crystallites has not been identified, their occurrence on the surface of the nanocomposites can still be reasonably correlated to the presence of doping element by reference to XPS and XAS measurements described hereafter. As mentioned for platinum-doped tin colloid, XPS surface analysis (Fig. 5) is again consistent with the conservation of a core-shell structure consisting in a core of tin(0) surrounded by a tin oxide layer on which the added palladium is deposited, the atom ratio $[\mathrm{Pd}] /[\mathrm{Sn}]$ decreasing from 1.9 to $1.4 \%$ after a $1 \mathrm{~min}$ argon bombardment of the sample.

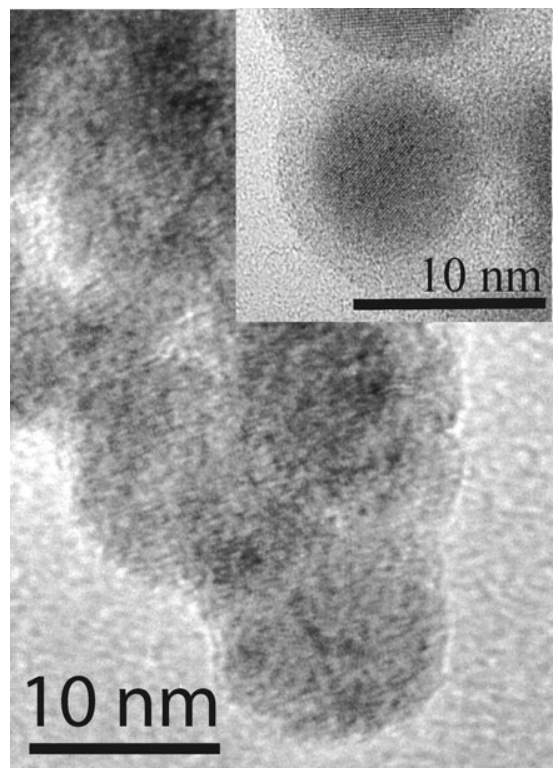

Fig. 2 HRTEM images of tin/tin oxide nanoparticles before (inset) and after Pt-doping.
If the palladium oxidation state can not be deduced from the XPS experiment, the $\mathrm{Pd} 3 \mathrm{~d}_{5 / 2}$ peak at $335.8 \mathrm{eV}$ being too close to those reported both for Pd metal and PdO,${ }^{49}$ XANES and EXAFS analyses clearly indicate that palladium is zerovalent and has a structure close to the metal but with a nanoparticle morphology and/or an amorphous character. ${ }^{42}$ EXAFS refinement shows that $\mathrm{Pd}$ atoms are surrounded by ca. 2.6 Sn at a short distance of $2.58 \AA$, and by a second coordination shell of $c a$. $2.3 \mathrm{Pd}$ atoms located at a longer distance of $2.77 \AA$, close to the typical Pd-Pd distances found in the pure Pd metallic phase. ${ }^{42}$

This result is consistent with the location of $\mathrm{Pd}$ atoms in the as-prepared sample in two metallic phases, i.e. a pure Pd metal one accounting for $20 \%$ of the total of $\mathrm{Pd}$ atoms and a mixed $\mathrm{Sn} / \mathrm{Pd}$ metallic phase for the rest of them. The combination of the XAS, XPS and HRTEM results suggests that Pd atoms are forming mainly small crystalline platelets of pure Pd metal coated with Sn atoms and embedded in the outer amorphous tin oxide layer of the nanoparticles. These results clearly demonstrate the absence of homogeneous mixing of the Pd atoms in the $\mathrm{Sn}$ matrix as is the case in the volume Pd-doped tin/tin oxide nanocomposite. ${ }^{42}$ Indeed, in the latter nanomaterials that feature a much bigger size and a smaller amount of $\mathrm{Pd}$ atoms in a pure $\mathrm{Pd}$ metallic phase $(4 \%)$, most of the $\mathrm{Pd}$ atoms are forming a mixed $\mathrm{Pd} / \mathrm{Sn}$ phase located in the metallic core of the particle.

\section{Oxidation of $\left[\mathrm{Sn} / \mathrm{SnO}_{x} / \mathrm{Pt}\right]$ and $\left[\mathrm{Sn} / \mathrm{SnO}_{x} / \mathrm{Pd}\right]$ nanoparticles}

As schematized below (Scheme 2), the doped tin nanoparticles can be fully oxidized in air, in an oven, at temperatures ranging from 50 to $525{ }^{\circ} \mathrm{C}$ according to the optimized multistep process already used for the oxidation of $\left[\mathrm{Sn} / \mathrm{SnO}_{x}\right]$ nanoparticles, ${ }^{35}$ to yield black solids.

This black solid is essentially constituted of crystallized tin dioxide as shown by their XRD patterns (which exhibit the classical quadratic cassiterite phase of $\mathrm{SnO}_{2}$ and, to a lesser extent, the high-pressure orthorhombic phase of $\mathrm{SnO}_{2}$ ). The apparent black colour of this solid is then consistent with the presence of palladium or platinum oxide at the surface of the material. The micrograph of platinum doped material (Fig. 6) 


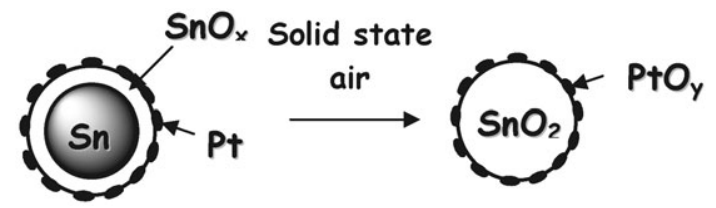

Scheme 2

shows individual agglomerated particles and displays the same type of morphology as the non-oxidized particles. Their mean size, around $13 \mathrm{~nm}$, as well as their size distribution are unchanged and no sign of coalescence can be observed. The HRTEM micrograph shows well-crystallized domains at the surface of the particles.

In order to confirm these results, an XPS study of the surface of the oxidized platinum doped tin particles as well as an XAS study of the oxidized palladium doped tin particles were performed. XPS spectra of the oxidized Pt-doped tin particles provides evidence of the presence of oxidized tin insofar as they feature one single symmetrical peak at 486.4 $\mathrm{eV}$ corresponding to the $\mathrm{Sn} 3 \mathrm{~d}_{5 / 2}$ electrons (Fig. 7). No $\mathrm{Sn}^{0}$ is observed even after argon bombardment. The position of the $\mathrm{Pt} 4 \mathrm{f}_{7 / 2}$ emission peak, i.e. $75.0 \mathrm{eV}$, is indicative of the presence

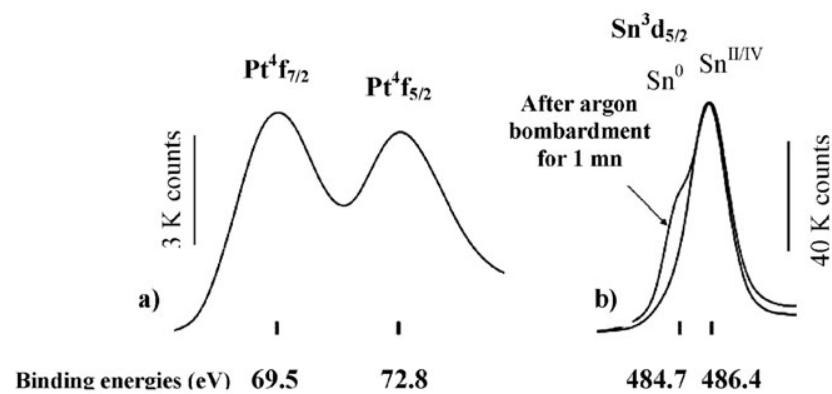

Fig. 3 Pt $4 \mathrm{f}$ (a) and $\mathrm{Sn} 3 \mathrm{~d}_{5 / 2}$ (b) emission peaks of the XPS spectrum of platinum-doped tin/tin oxide nanoparticles (arbitrary units on $y$ scales).

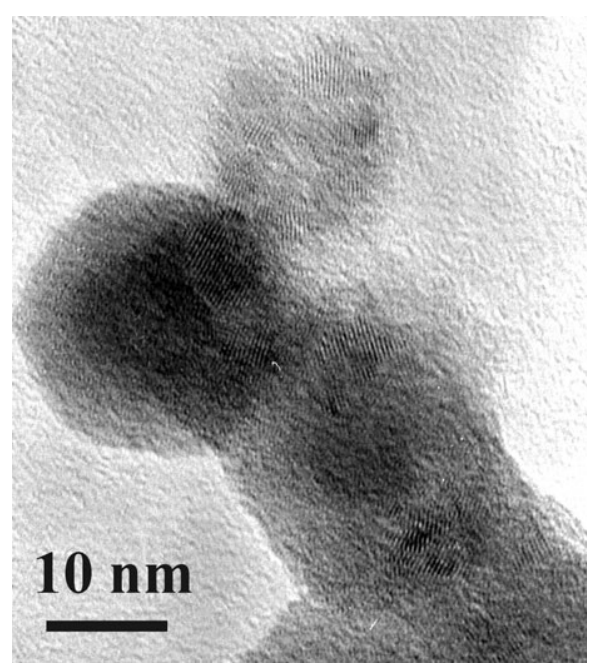

Fig. 4 HRTEM image of palladium-doped tin/tin oxide nanoparticles.

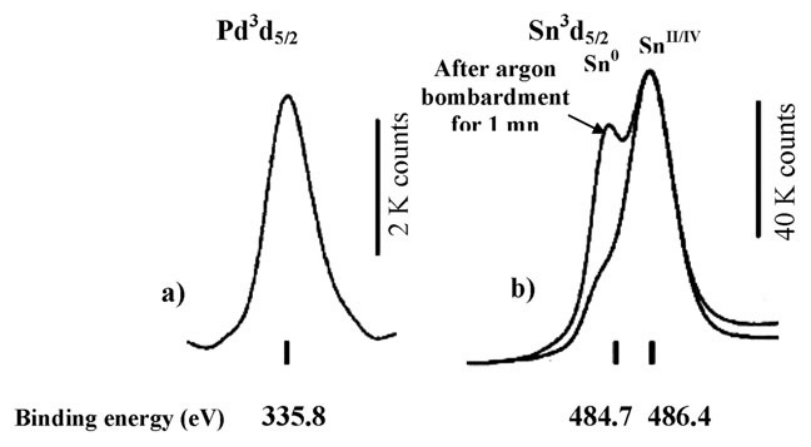

Fig. $5 \mathrm{Pd} 3_{5 / 2}$ (a) and $\operatorname{Sn} 3 \mathrm{~d}_{5 / 2}$ (b) emission peaks of the XPS spectrum of palladium-doped tin/tin oxide nanoparticles (arbitrary units on $y$ scale).

of an oxidized $\mathrm{PtO}_{2}$ phase at the surface of the particles. ${ }^{49}$ The side peaks observed at lower binding energies i.e. between 71.5 and $74.0 \mathrm{eV}$ can be assigned, respectively, to $\mathrm{Pt}(\mathrm{OH})_{2}, \mathrm{PtO}$ and/or $\mathrm{Pt}-\mathrm{O}-\mathrm{Sn}$ phases by reference to previous studies. ${ }^{50}$ Moreover, after a 1 min argon bombardment, the $\mathrm{Pt} 4 \mathrm{f}_{7 / 2}$ peak is strongly shifted towards a position at higher binding energy, i.e. $72.1 \mathrm{eV}$, very close to that previously reported for the $\mathrm{Pt}-\mathrm{O}-\mathrm{Sn}$ surface species $^{51}$ which are supposed to model the platinum chemisorption on tin dioxide. Our observations suggest a core-shell structure for the nanocomposite $\mathrm{SnO}_{2}$ / $\mathrm{PtO}_{2}$ in which platinum dioxide lies at the surface of tin dioxide particles through an interface constituted of $\mathrm{SnO}_{2}-$ bonded $\mathrm{Pt}$ species and rule out the presence of metallic platinum at the surface of tin oxide grains, in agreement with previous observations. ${ }^{52}$

\section{XAS studies of the fully oxidized Pd-doped $\mathrm{Sn} / \mathrm{SnO}_{x}$ nanoparticles}

XANES spectra of the Pd doped nanomaterial as-prepared and after its full oxidation along with pure $\mathrm{PdO}$ and bulk $\mathrm{Pd}$ metal references are presented in Fig. 8.

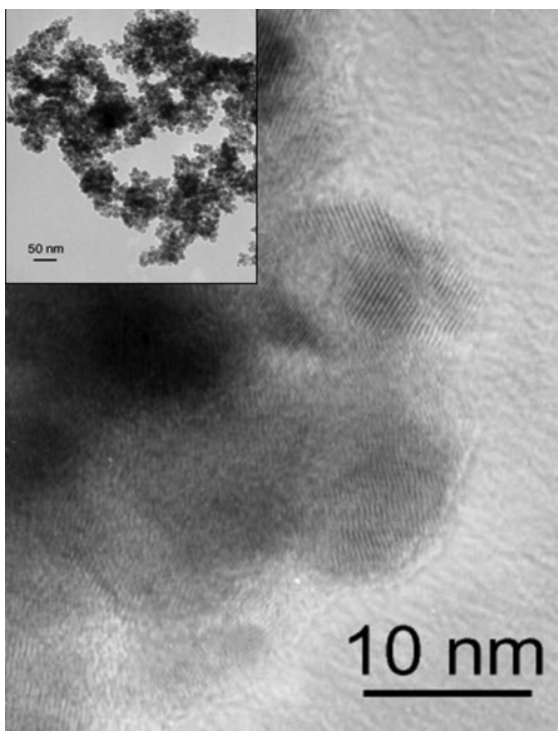

Fig. 6 TEM (inset) and HRTEM images of platinum-doped tin/tin oxide particles after oxidation. 


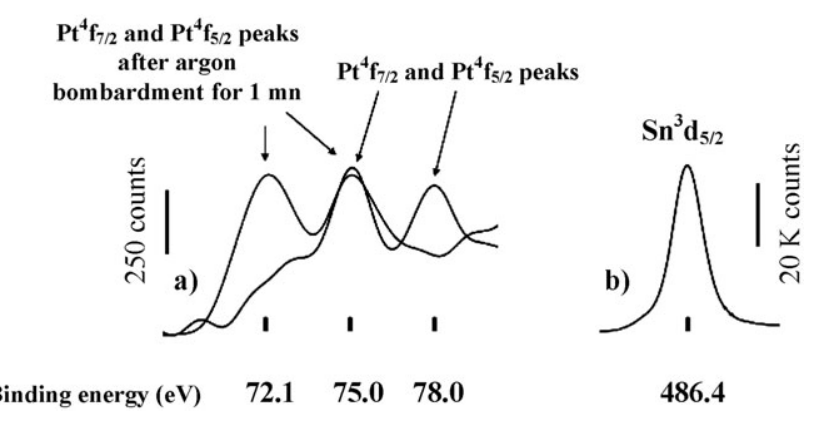

Fig. $7 \mathrm{Pt} 4 \mathrm{f}$ (a) and $\mathrm{Sn} 3 \mathrm{~d}_{5 / 2}$ (b) emission peaks of the XPS spectrum of platinum-doped tin/tin oxide nanoparticles after oxidation (arbitrary units on $y$ scales).

It is clear that the XANES profile of the as-prepared nanomaterial spectrum features the same oscillations, although less intense, than that corresponding to the bulk $\mathrm{Pd}$ metal and that $\mathrm{Pd}$ in this material is in a metallic state. On the other hand, the edge position as well as the shape of the XANES spectrum of the fully oxidised nanoparticles is very similar to that of the $\mathrm{PdO}$ reference sample indicating that $\mathrm{Pd}$ atoms in this material are certainly forming an oxide phase close to PdO. However a closer comparison of these two spectra reveals some differences in their profile such as different oscillations indicating that the $\mathrm{Pd}$ oxide in this phase is not pure $\mathrm{PdO}$ and may instead consist of a mixture of $\mathrm{PdO}$ with another Pd-based oxidic phase.

The comparison of the phase-corrected FTs corresponding to the EXAFS measurements at the Pd K-edge of the asprepared and oxidised sample along with $\mathrm{Pd}$ metal foil and $\mathrm{PdO}$ reference samples presented in Fig. 9 leads apparently to the same preliminary conclusions. The main peak in the FT of the as-prepared sample is located roughly at the same position as the main peak in the FT of the Pd metal. Similarly the main

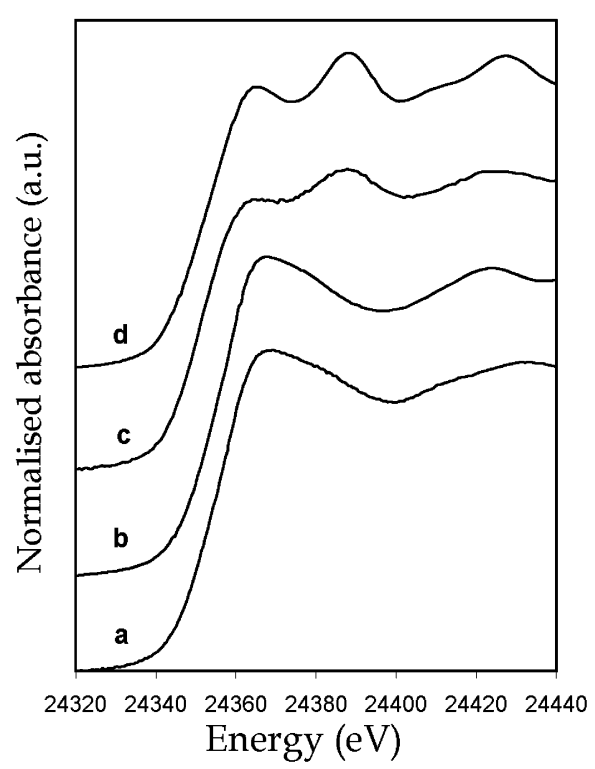

Fig. 8 Pd K-edge normalised XANES spectra of (a) fully oxidized Pd surface-doped $\mathrm{Sn} / \mathrm{SnO}_{x}$ nanomaterial, (b) bulk $\mathrm{PdO}$, (c) as-prepared surface-doped $\mathrm{Sn} / \mathrm{SnO}_{x}$ nanomaterial and (d) bulk Pd metal.

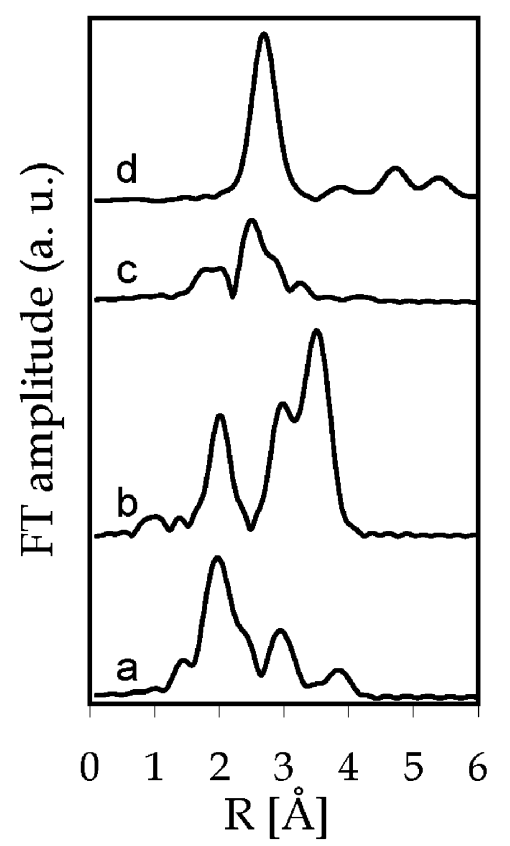

Fig. 9 Fourier transforms of the Pd K-edge $k^{3}$-weighted or $k^{2}$ weighted EXAFS of (a) fully oxidized Pd surface-doped $\mathrm{Sn} / \mathrm{SnO}{ }_{x}$ nanomaterial, (b) bulk PdO, (c) as-prepared surface-doped $\mathrm{Sn} / \mathrm{SnO}{ }_{x}$ nanomaterial and (d) bulk Pd metal.

peak in the oxidised sample is located at the same position as the first peak of the FT corresponding to PdO. It can be noticed that in the case of the oxidised nanomaterial this first peak presents a shoulder that is absent in the $\mathrm{PdO}$ reference sample. As expected, the strong multipeak corresponding to long distance shells in the crystalline structure of $\mathrm{PdO}$ has almost disappeared in the nanomaterial, due to the lack of long-distance order in these nanomaterials.

Results of the EXAFS structural refinements are summarised in Table 1. The EXAFS and Fourier transform best fits are, respectively presented in Fig. 10 and 11 .

The FT of the oxidised surface-doped sample shows three relatively sharp peaks of decreasing intensities, respectively located before phase correction at around 1.6, 2.5 and $3.4 \AA$. The main peak located at $\sim 1.6 \AA$ features a shoulder on its right hand side indicating the presence of two shells with close distances.

The low intensity of the second and third peaks already shows that the local environment around $\mathrm{Pd}$ atoms is relatively disordered and that the $\mathrm{Pd}$ phase is part of a rather amorphous phase and/or that this phase is composed of very small particles.

The results of the EXAFS refinement presented in Table 1 show that the first peak could be fitted with two oxygen shells of respectively, 3.1 atoms located at $2.02 \AA$ and 2.2 oxygen atoms located at $2.51 \AA$. The second peak could be fitted with 2.0 tin atoms located at $2.69 \AA$. The higher- $R$ part of the FT corresponds to a Pd shell of 3.0 atoms located at $3.27 \AA$ and two additional shells of $c a$. 0.4 Pd at 3.06 and 0.5 Sn at $3.69 \AA$.

The first oxygen bond distance is very similar to the corresponding first $\mathrm{Pd}-\mathrm{O}$ bond distance in the $\mathrm{PdO}$ phase 
Table 1 Summary of structural results of Pd K-edge EXAFS refinements of the oxidised $\mathrm{Pd}$ doped $\mathrm{Sn} / \mathrm{SnO}_{x}$ nano-materials along with bulk Pd and bulk PdO

\begin{tabular}{|c|c|c|c|}
\hline & Bulk Pd & $\mathrm{PdO}$ & $\begin{array}{l}\mathrm{Pd} \text { surface-doped } \\
\mathrm{Sn} / \mathrm{SnO}_{x}\end{array}$ \\
\hline$E_{\mathrm{f}}^{a}$ & $-0.4(2)$ & $4.7(7)$ & $4.6(6)$ \\
\hline $\mathrm{AFAC}^{b}$ & 0.85 & 0.85 & 0.85 \\
\hline$k$ & 3 & 3 & 2 \\
\hline$k$-range & $3-16$ & $3-15$ & $2.6-12.6$ \\
\hline$N_{1}{ }^{c}$ & $12 * \mathrm{Pd}$ & $4 * \mathrm{O}$ & $3.1(2) \mathrm{O}$ \\
\hline$R_{1}^{d}$ & $2.737(1)$ & $2.005(1)$ & $2.019(3)$ \\
\hline$A_{1}{ }^{e}$ & $0.0100(1)$ & $0.003(1)$ & $0.005(1)$ \\
\hline $\mathrm{N}_{2}$ & 6* $\mathrm{Pd}$ & $4 * \mathrm{Pd}$ & $2.2(3) \mathrm{O}$ \\
\hline$R_{2}$ & $3.87(1)$ & $3.030(2)$ & $2.514(9)$ \\
\hline$A_{2}$ & $0.018(4)$ & $0.004(1)$ & $0.016(1)$ \\
\hline$N_{3}$ & $24^{*} \mathrm{Pd}$ & $8 * \mathrm{Pd}$ & $2.0(3) \mathrm{Sn}$ \\
\hline$R_{3}$ & $4.741(6)$ & $3.416(4)$ & $2.693(8)$ \\
\hline$A_{3}$ & $0.016(2)$ & $0.005(1)$ & $0.015(5)$ \\
\hline$N_{4}$ & $12 * \mathrm{Pd}$ & - & $0.4(2) \mathrm{Pd}$ \\
\hline$R_{4}$ & $5.47(2)$ & - & $3.06(2)$ \\
\hline$A_{4}$ & $0.023(3)$ & - & $0.001(8)$ \\
\hline$N_{5}$ & $24 \mathrm{Pd}$ & - & 3.0(4) $\mathrm{Pd}$ \\
\hline$R_{5}$ & $6.13(3)$ & - & $3.27(2)$ \\
\hline$A_{5}$ & $0.028(1)$ & - & $0.035(9)$ \\
\hline$N_{6}$ & - & - & $0.5(2) \mathrm{Sn}$ \\
\hline$R_{6}$ & - & - & $3.69(2)$ \\
\hline$A_{6}$ & - & - & $0.0001(10)$ \\
\hline$R(\%)$ & 15.3 & 17.7 & 10.5 \\
\hline
\end{tabular}

${ }^{a} E_{\mathrm{f}}=$ Contribution of the wave vector of the zero photoelectron relative to the origin of $k[\mathrm{eV}] .{ }^{b} \mathrm{AFAC}=$ Amplitude reduction due to many-electron processes. ${ }^{c} N_{i}=$ Number of atoms in the $i^{\text {th }}$ shell. ${ }^{d} R_{i}$ $=$ Radial distance of atoms in the $i^{\text {th }}$ shell $[\AA] .{ }^{e} A_{i}=$ Debye-Waller term of the $i^{\text {th }}$ shell ( $A=2 \sigma^{2}$ with $\sigma=$ Debye-Waller factor) $\left[\AA^{2}\right]$. *These parameters were kept fixed during the refinement. Bulk Pd (fcc): $a=3.8898 \AA, 12 \mathrm{Pd}$ at $2.751 \AA, 6 \mathrm{Pd}$ at $3.890 \AA{ }^{45}$ Bulk PdO: $P 4_{2} / m m c, a=b=3.03, c=5.33 \AA, 4 \mathrm{O}$ at $2.018 \AA, 2 \mathrm{Pd}$ at $2.665 \AA$,

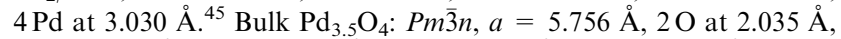
$4 \mathrm{O}$ at $2.492 \AA, 1 \mathrm{Pd}$ at $2.878 \AA, 8 \mathrm{Pd}$ at $3.218 \AA$, 4 Pd at $3.525 \AA .{ }^{45}$ Bulk $\mathrm{SnO}_{2}$ (cassiterite): $P 4_{2} / m n m ; a=b=4.737, c=3.185 \AA$; $4 \mathrm{O}$ at 2.051 $\AA, 2 \mathrm{O}$ at $2.057 \AA, 4 \mathrm{O}$ at $3.590 \AA$, $2 \mathrm{Sn}$ at $3.185 \AA$, $8 \mathrm{Sn}$ at $3.709 \AA{ }^{45}$ Bulk SnO (romarchite): $P 4 / n m m, a=b=3.796, c=4.816 \AA$; $4 \mathrm{O}$ at $2.211 \AA$, 4 Sn at $3.515 \AA, 4$ Sn at $3.700 \AA^{45}$

$(2.018 \AA)$ indicating that, in agreement with the XANES analysis, a significant amount of this phase may be present. However, the second oxygen shell located at $2.51 \AA$ that does not belong to this phase may suggest the occurrence of an oxopalladate $\mathrm{Pd}_{3.5} \mathrm{O}_{4}$-type phase. ${ }^{53}$ Indeed, this latter phase features in addition to a short $\mathrm{Pd}-\mathrm{O}$ bond distance of $2.035 \AA$ close to the first $\mathrm{Pd}-\mathrm{O}$ bond distance in $\mathrm{PdO}$, longer $\mathrm{Pd}-\mathrm{O}$ bonds with a very similar distance of $2.492 \AA$. The EXAFS analysis of the oxygen shells, in agreement with the XANES observations, strongly suggests that two different Pd oxide phases coexist in this nanomaterial. The relatively high Debye-Waller factor associated with this second shell $\mathrm{O}$ shell indicates that the $\mathrm{Pd}_{3.5} \mathrm{O}_{4}$ phase is highly disordered.

The general fit was greatly improved by fitting the second shell with Sn atoms instead of the Pd that would be normally

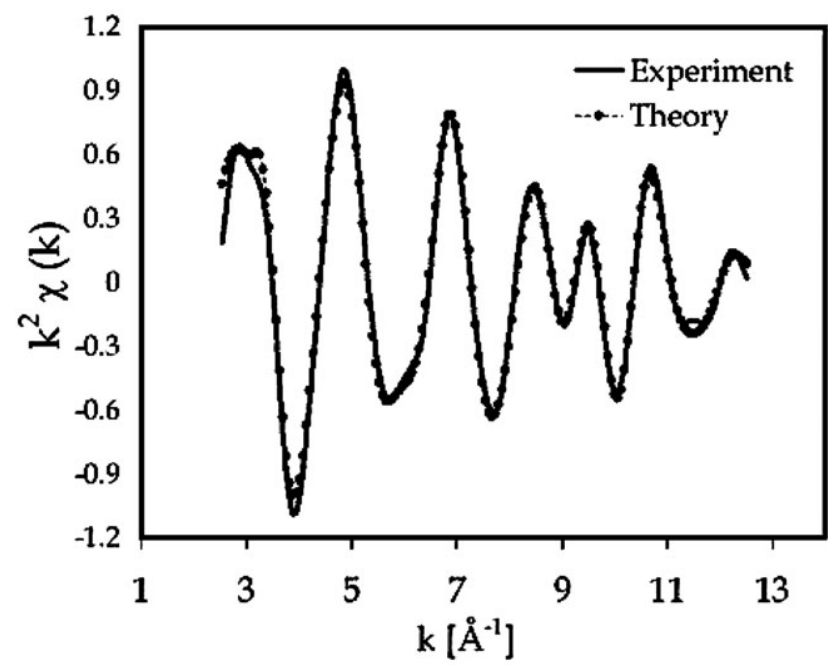

Fig. 10 Pd K-edge EXAFS spectra (after background subtraction, $k^{2}$-weighed) of the fully oxidized $\mathrm{Pd}$ surface-doped $\mathrm{Sn} / \mathrm{SnO}_{x}$ nanomaterial. The solid lines are the experimental data and the dotted line is the best fit.

expected as second neighbours in a Pd oxide phase. The distance of this Sn shell is very close to the typical Pd-Pd bond of the PdO phase $(2.665 \AA)$ but with a slightly larger value $(2.693 \AA)$. This could correspond to a Sn atom substituting a Pd atom in a PdO type phase. The next shell of the FT was fitted with $0.4 \mathrm{Pd}$ atoms located at a distance of $3.06 \AA$ that is very close to the third Pd-Pd bond distance $(3.030 \AA)$ observed in the PdO phase. The formation of a relatively disordered and/or nanocrystalline mixed $\mathrm{Pd} / \mathrm{Sn}$ oxide phase with a structure similar to that of $\mathrm{PdO}$ seems to be the best explanation to account for these results.

The next shell corresponds to $3.0 \mathrm{Pd}$ atoms located at $3.27 \AA$ in the same range as the $\mathrm{Pd}-\mathrm{Pd}$ bond distance of the $\mathrm{Pd}_{3.5} \mathrm{O}_{4}$ phase $(3.218 \AA$ ). The presence of this shell is another argument in favour of the occurrence of a $\mathrm{Pd}_{3.5} \mathrm{O}_{4}$-type phase in these samples. Contrarily to the other oxide phase, this $\mathrm{Pd}_{3.5} \mathrm{O}_{4}$-type

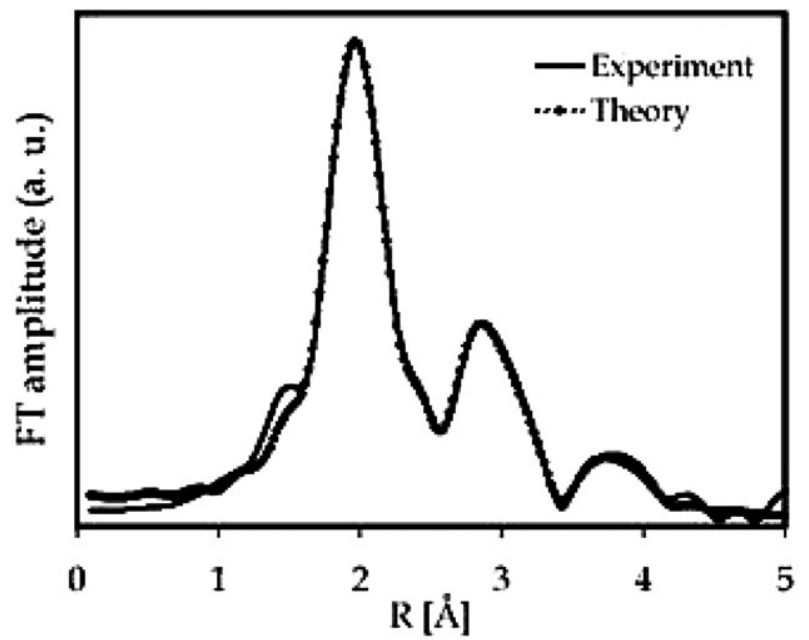

Fig. 11 Fourier transform of the Pd K-edge $k^{2}$-weighted of the fully oxidized Pd surface-doped $\mathrm{Sn} / \mathrm{SnO}_{x}$ nanomaterial. The solid lines are the experimental data, the dotted line is the best fit. 
phase seems to be a pure Pd phase without Sn atoms in its structure.

The last shell that could be included in the fitting model is a Sn shell at 3.69 A that does not correspond to any atomic shell in any of the existing $\mathrm{Pd}$ oxide phases. This distance could however correspond to a $\mathrm{Sn}-\mathrm{Sn}$ distance found in the $\mathrm{SnO}_{2}$ (3.709 $\AA$ ) phase meaning that a small part of the Pd atoms may be incorporated in the $\mathrm{SnO}_{2}$ phase that comprises these nanocomposites.

Because the oxygen shell located at $2.51 \AA$ only belongs to the $\mathrm{Pd}_{3.5} \mathrm{O}_{4}$ phase, a rough evaluation of the relative ratio of the Pd atoms in this phase can be simply done by using the corresponding coordination number. The number of the oxygen located at this distance in the Pd doped nanomaterial is 2.2 compared to 4 atoms in the $\mathrm{Pd}_{3.5} \mathrm{O}_{4}$ phase which gives a ratio of $c a$. $(2.2 / 4) \times 100=55 \%$ of $\mathrm{Pd}$ atoms in the $\mathrm{Pd}_{3.5} \mathrm{O}_{4}$ phase in the nanomaterial.

A possible interpretation of the changes occurring during the full oxidation of this nanomaterial would be a transformation of the pure $\mathrm{Pd}$ metallic platelets into a pure disordered $\mathrm{Pd}_{3.5} \mathrm{O}_{4}$ phase whilst the mixed metallic phase that was present at the interface platelet/ $\mathrm{SnO}_{x}$ and to a lesser extent in the core of the particle is transformed into two phases: a mixed $\mathrm{Pd} / \mathrm{Sn}$ oxide having a $\mathrm{PdO}$ type structure and, to a lesser extent, a $\mathrm{SnO}_{2}$ phase in which some $\mathrm{Sn}$ are substituted by $\mathrm{Pd}$ atoms. This model would be in good agreement with the HRTEM picture presented in Fig. 6 that clearly shows the presence of platelets at the surface of the Pd-doped nanoparticles. The discrepancy between the relative amounts of $\mathrm{Pd}_{3.5} \mathrm{O}_{4}$ phase (ca. 55\%) in the oxidised sample compared to $c a .20 \%$ of $\mathrm{Pd}$ metal in the as-prepared material may be explained by a higher amount of Pd metal in the as-prepared sample. Indeed, the evaluation $^{42}$ was made using as a reference, a Pd coordination number of 12 corresponding to the bulk Pd metal; this figure could be too large for a highly dispersed nanomaterial. An additional phenomenon of atom migration at the interface core/outer layer/Pd platelets may also be involved in the oxidation process explaining this discrepancy.

This XAS study points out the complex structure of these $\mathrm{Pd}$ doped samples that seem similar to that of the $\mathrm{SnO}_{2} / \mathrm{PtO}_{2}$ nanocomposite. Indeed, these $\mathrm{Pd}$ doped materials consist apparently of a core-shell structure in which a disordered $\mathrm{Pd}_{3.5} \mathrm{O}_{4}$-type phase, instead of $\mathrm{PtO}_{2}$ in its $\mathrm{Pt}$ doped counterpart, lies at the surface of tin dioxide particles through an interface of $\mathrm{SnO}_{2}$-bonded $\mathrm{Pd}$ species forming a mixed $\mathrm{Pd} / \mathrm{Sn}$ $\mathrm{PdO}$ structure-type phase with no metallic palladium at the surface of the tin oxide grains.

\section{Resistance measurements and gas sensing properties}

Gas sensitivity measurements were performed in order to systematically compare the influence of doping and humidity content on the sensor responses towards carbon monoxide. A drop of doped or undoped tin nanoparticles in suspension in anisole was deposited between the electrodes of a gas-sensing device integrated onto a silicon platform. Resistance measurements were carried out after evaporation of the solvent and in situ oxidation of the nanoparticles according to a multistep process similar to that used for the oxidation in an oven.
The as-obtained microsensors have been exposed to test gases, i.e. $\mathrm{CO}(5,25$ and $50 \mathrm{ppm}$ in synthetic air) under a humidity content of $50 \%$ and at a working temperature of the sensitive layer near $450{ }^{\circ} \mathrm{C}$. Palladium and platinum doping considerably affect the resistances of the sensing materials that typically increase from values close to $20 \mathrm{k} \Omega$ for the undoped sensors to $100 \mathrm{k} \Omega$ for the doped materials. The introduction of small amount of carbon monoxide in the test gas is accompanied by a fast decrease in resistance, which is the normal behaviour usually observed toward reducing gases. This variation of resistance, expressed by the ratio $S=\left[\left(R_{\text {gas }}-R_{0}\right) /\right.$ $R_{0}$ ] $\times 100$ ( $S$ is the sensitivity value, $R_{\text {gas }}$ and $R_{0}$ are the resistances under test-gases and air, respectively), is strongly affected by the doping of the sensitive layer. Typically, the sensitivity values $S$ under $50 \mathrm{ppm}$ of CO are respectively -10 , -50 and $-70 \%$ for undoped, Pd- and Pt-doped $\mathrm{SnO}_{2}$ sensitive layers. The sensitivity of the undoped and Pd- and Pt-doped sensing materials is obviously dependant on the CO content present in the test gas. Typical values of sensitivity for Pt-doped sensors are respectively $-70,-85$ and $-92 \%$ under 5,25 and $50 \mathrm{ppm}$ of CO. The reproducibility and the stability of these measurements have been checked on several series of sensors maintained under similar working conditions over a period of one year.

Humidity appears to be a major parameter that strongly influences the response of the sensors. Fig. 12 shows the resistance variations of undoped and $\mathrm{Pd}$-doped tin dioxide sensitive layers working near $450{ }^{\circ} \mathrm{C}$ when exposed to increasing amounts of carbon monoxide, e.g. from 50 to $500 \mathrm{ppm}$, in dry air. Surprisingly, the responses of these two types of sensors to carbon monoxide are characterized by opposite variations in the resistances, i.e., a decrease in resistance for the undoped sensitive layer, which is the usually observed behaviour in the presence of a reducing gas, and a sharp increase in resistance for the palladium-doped sensitive layers. Quite similar behaviours have also been observed for Pt-doped tin dioxide sensitive layers.

The response to $\mathrm{CO}$ of $\mathrm{Pd}$-doped sensitive layers is in fact dramatically dependant on humidity and Fig. 13 shows that the introduction of a small amount of humidity is

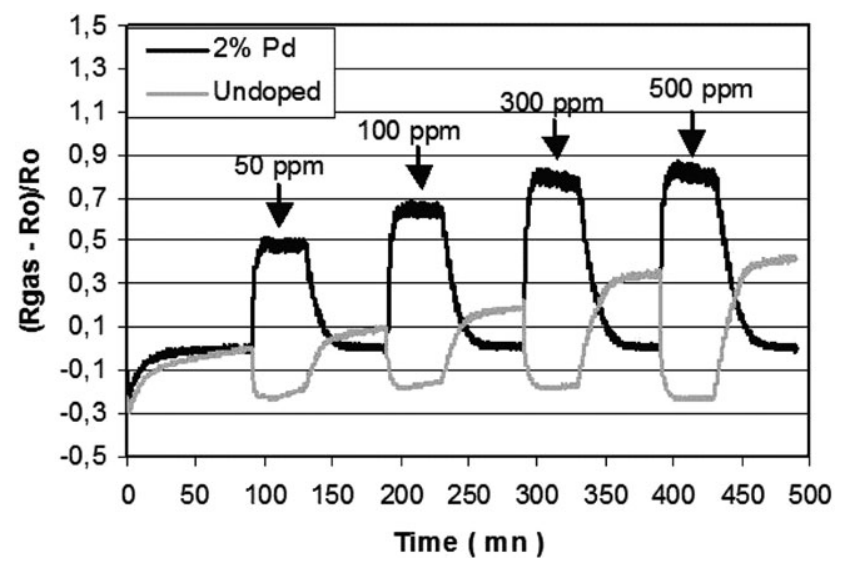

Fig. 12 Undoped and Pd-doped sensor responses to CO under dry air. 


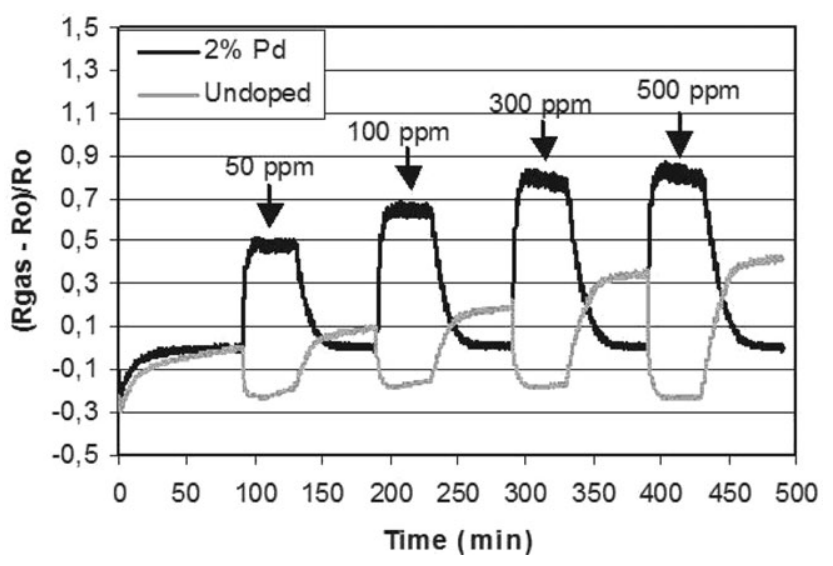

Fig. 13 Pd-doped sensitive layers responses to CO in dry and humid atmospheres.

accompanied by opposite variations of resistances under $\mathrm{CO}$, whereas Fig. 14 shows that the humidity dependence on the sensitivity $S$ toward CO is quite different according to whether the sensitive layer is doped or not. For Pd-doped sensitive layers, a zero-sensitivity to $50 \mathrm{ppm}$ of $\mathrm{CO}$ is observed for humidity content close to $5 \%$. Then the sensitivity increases up to values in the range $[-50,-60 \%]$ when humidity content RH increases from 20 to $55 \%$. Under similar conditions and within the same limits of humidity content, undoped tin oxide layers exhibit smaller sensitivity values stabilized around $-10 \%$.

This behaviour is reversible and the increase in resistance under $\mathrm{CO}$ can be observed again after a time exposure of the sensor to dry air for few hours under working conditions (flow-rate of $1 \mathrm{~L} \mathrm{~min}{ }^{-1}$ and a constant temperature near $450{ }^{\circ} \mathrm{C}$ for the sensitive layer).

The accepted detection mechanism of reducing gases such as $\mathrm{CO}$ involves the partial reduction of the surface of the sensitive layer. The result of this reduction is an increase in the conductivity of the sensitive layer. The inversion of sensitivity toward CO from undoped to Pd- and Pt-doped sensors is therefore surprising and presently under investigation.

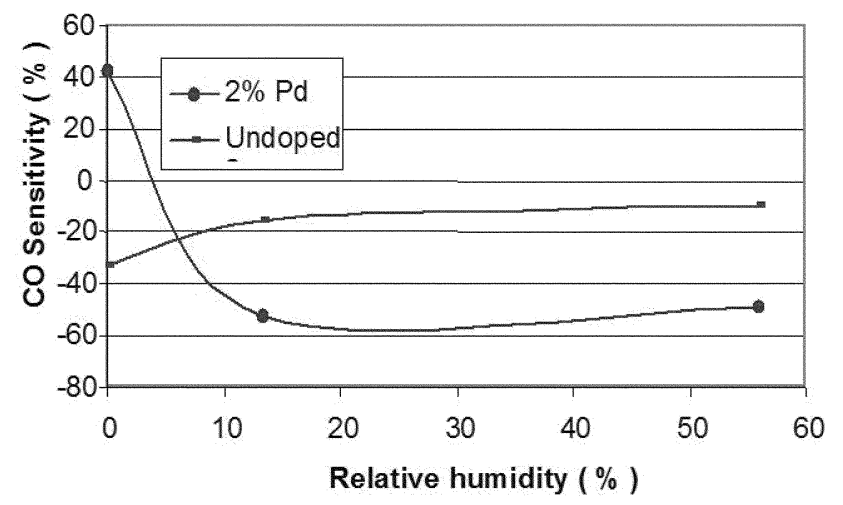

Fig. 14 Humidity dependence of undoped and Pd-doped sensors under $50 \mathrm{ppm}$ of $\mathrm{CO}$.

\section{Conclusions}

This study demonstrates that the organometallic route is a powerful tool for an accurate doping of tin dioxide nanoparticles that can be easily implemented in microsensor technology. For this purpose, we have achieved a high yield doping process consisting first in the doping of the nanocomposite $\left[\mathrm{Sn} / \mathrm{SnO}_{x}\right]$ through the decomposition of Pd or Pt organometallic precursors, followed by the thermal oxidation under air of the as-obtained Pd- or Pt-doped material.

The first interesting aspect of this approach is that neither the doping process nor the subsequent thermal treatments affect the morphology of the as-prepared tin/tin oxide materials, all nanoparticles isolated at each step of the process having mean sizes around $13 \mathrm{~nm}$ with narrow size distributions, as observed for the starting material. Combination of XAS and/or XPS techniques together with HRTEM show that in both cases the doping element is homogeneously localized at the surface of the $\mathrm{Sn} / \mathrm{SnO}_{x}$ particles forming crystalline metallic platelets having sizes close to $2 \mathrm{~nm}$, whereas the full oxidation of both Pt and Pd doped materials yields composite nanoparticles that are likely consisting of a core of crystalline tin dioxide surrounded, respectively, by disordered crystalline platelets of $\mathrm{PtO}_{2}$ or $\mathrm{Pd}_{3.5} \mathrm{O}_{4}$ oxides. The latter phases are linked to the $\mathrm{SnO}_{2}$ core of the particle, respectively, through a mixed $\mathrm{Pt} / \mathrm{Sn}$ and a mixed $\mathrm{Pd} / \mathrm{Sn}$ oxide phase.

The second interesting aspect is that, as the undoped $\mathrm{Sn} /$ $\mathrm{SnO}_{x}$ nanoparticles, Pd- or Pt-doped $\mathrm{Sn} / \mathrm{SnO}$ c can be easily deposited onto silicon platforms and implemented as a sensitive layer of a micromachined silicon gas sensor. Finally, the as-obtained gas sensors show remarkable behaviours when exposed to carbon monoxide: (i) a surprising inversion of sensitivity toward carbon monoxide in dry atmosphere (RH $<5 \%$ ) when going from undoped to Pd- or Pt-doped sensors and (ii) an important increase in sensitivity to $\mathrm{CO}$ under humidity level in the range $15-55 \%$ of doped sensitive layers relative to undoped one. Current and future studies are oriented towards the understanding of this unprecedented behaviour, which is believed to be basically related to the detection phenomena at the surface of the material. This includes behavioural studies of the doped sensitive layers toward other reducing gases such as $\mathrm{H}_{2}$ or hydrocarbons and towards oxidizing gases such as $\mathrm{NO}_{2}$ and $\mathrm{O}_{3}$.

\section{Acknowledgements}

The authors thank the CNRS and the European Commission for funding this work within the NANOSENSOFLEX project (GROWTH-G5RD-CT-2002-00722). We express our gratitude to M. Vincent Collière, Lucien Datas, and UPS-TEMSCAN facility for TEM measurements, M. Gérard Chatainier, and INPT-ENSIASET for ESCA measurements, Dr François Senocq for XRD measurements, Ad van der Eerden (Utrecht University) and Dr Julia Wienbold (X1, Hasylab) for their assistance and advise during the XAFS measurement experiments. We also wish to acknowledge the use of the EPSRCs Chemical Database Service at Daresbury. 


\section{References}

1 K. Murakami, S. Yasunaga, S. Sunahara and K. Ihokura, Anal. Chem. Symp. Ser., 1983, 17, 18-23.

2 D. E. Williams, in Solid State Gas Sensors, ed. P. T. Moseley and B. C. Tofield, Adam Hilger, Bristol, 1987, p. 71.

3 V. Lantto, in Gas Sensors, Principle, Operation and Developments, ed. G. Sberveglieri, Kluwer Academic, Dordrecht, Boston, London, 1992, p. 117.

4 K. Ihokura and J. Watson, The Stannic Oxide Gas Sensor: Principles and Applications, CRC Press, Boca Raton, FL, 1994.

5 Technical information for carbon monoxide sensors, Figaro Engineering Inc. website.

6 A. Heilig, N. Barsan, U. Weimar, M. Schweizer-Berberich, J. W. Gardner and W. Göpel, Sens. Actuators, B, 1997, 43, 45-51.

7 I. Simon, N. Bârsan, M. Bauer and U. Weimar, Sens. Actuators, B, 2001, 73, 1-26.

8 U. Weimar and W. Göpel, Sens. Actuators, B, 1995, 26-27, 13-18.

9 M. Schweizer-Berberich, M. Zdralek, U. Weimar, W. Göpel, T. Viard, D. Martinez, A. Seube and A. Peyre-Lavigne, Sens. Actuators, $B, 2000, \mathbf{6 5}, 91-93$.

10 N. Yamazoe, Sens. Actuators, B, 1991, 5, 7-19.

11 W. Göpel, in Gas Sensors: Principle, Operation and Developments, ed. G. Sberveglieri, Kluwer Academic, Dordrecht, Boston, London, 1992 , p. 365.

12 W. Göpel and K. D. Schierbaum, Sens. Actuators, B, 1995, 26-27, $1-12$.

13 G. Sberveglieri, Sens. Actuators, B, 1995, 23, 103-109.

14 N. Yamazoe, Y. Kurokawa and T. Seiyama, Sens. Actuators, B, 1983, 4, 283-289.

15 J. O. W. Norris, in Solid State Gas Sensor, ed. P. T. Moseley and B. C. Tofield, Adam Hilger, Bristol, 1987, p. 124.

16 V. Demarne and R. Sanjines, in Gas Sensors: Principle, Operation and Developments, ed. G. Sberveglieri, Kluwer Academic, Dordrecht, Boston, London, 1992, p. 89.

17 M. Schweizer-Berberich, J. G. Zheng, U. Weimar, W. Göpel, N. Barsan, E. Pentia and A. Tomescu, Sens. Actuators, B, 1996, 31, 71-75.

18 M. Sauvan and C. Pijolat, Sens. Actuators, B, 1999, 58, 295-301.

19 Y. Shimizu and M. Egashira, MRS Bull., 1999, 24, 18-24.

20 M. Ivanovskaya and A. G. P. Bogdanov, Sens. Actuators, B, 2001, 77, 264-267.

21 A. Cirera, A. Cabot, A. Cornet and J. R. Morante, Sens. Actuators, $B, 2001,78,151-160$.

22 S. Matsushima, Y. Teraoka, N. Miura and N. Yamazoe, Jpn. J. Appl. Phys., 1988, 27, 1798-1802.

23 S. Matsushima, J. Tamaki, N. Miura and N. Yamazoe, Chem. Lett., 1989, 1651-1654.

24 M. Labeau, B. Gautheron, F. Cellier, M. Vallet-Regi, E. Garcia, J. M. Gonzalez and Calbet, J. Solid State Chem., 1993, 102, 434- 439.

25 A. Dieguez, A. Vila, A. Cabot, A. Romano Rodriguez, J. R. Morante, J. Kappler, N. Barsan, U. Weimar and W. Göpel, Sens.Actuators, B, 2000, 68, 94-99.

26 K. Soulantica, A. Maisonnat, M.-C. Fromen, M.-J. Casanove, P. Lecante and B. Chaudret, Angew. Chem., Int. Ed., 2001, 40, 448-451.

27 K. Soulantica, A. Maisonnat, F. Senocq, M.-C. Fromen, M.-J. Casanove and B. Chaudret, Angew. Chem., Int. Ed., 2001, 40, 2983-2986.
28 C. Pan, K. Pelzer, K. Philippot and B. Chaudret, J. Am. Chem. Soc., 2001, 123, 7584-7593.

29 N. Cordente, M. Respaud, F. Senocq, M.-J. Casanove, C. Amiens and B. Chaudret, Nano Lett., 2001, 1, 565-568.

30 F. Dumestre, B. Chaudret, C. Amiens, M.-C. Fromen, M.-J. Casanove, P. Renaud and P. Zurcher, Angew. Chem., Int. Ed., 2002, 41, 4286-4289.

31 K. Philippot and B. Chaudret, C. R. Chim., 2003, 6, 1019-1034.

32 K. Peltzer, O. Vidoni, K. Philippot, B. Chaudret and V. Collière, Adv. Funct. Mater., 2003, 13, 118-126.

33 F. Dumestre, B. Chaudret, C. Amiens, P. Renaud and P. Fejes, Science, 2004, 303, 821-823.

34 C. Nayral, T. Ould-Ely, A. Maisonnat, B. Chaudret, P. Fau, L. Lescouzeres and A. Peyre-Lavigne, Adv. Mater., 1999, 11, 61-63.

35 C. Nayral, E. Viala, P. Fau, F. Senocq, J.-C. Jumas, A. Maisonnat and B. Chaudret, Chem. Eur. J., 2000, 6, 4082-4090.

36 F. Rataboul, C. Nayral, M.-J. Casanove, A. Maisonnat and B. Chaudret, J. Organomet. Chem., 2002, 643-644, 311-316.

37 K. Soulantica, L. Erades, M. Sauvan, F. Senocq, A. Maisonnat and B. Chaudret, Adv. Funct. Mater., 2003, 13, 553-557.

38 M. Monge, M. L. Kahn, A. Maisonnat and B. Chaudret, Angew. Chem., Int. Ed., 2003, 42, 5321-5324.

39 C. Amiens, D. de Caro, B. Chaudret, J. Bradley, R. Mazel and C. Roucau, J. Am. Chem. Soc., 1993, 115, 11638-11639.

40 A. Duteil, R. Quéau, B. Chaudret, R. Mazel, C. Roucau and J. S. Bradley, Chem. Mater., 1993, 5, 341-347.

41 S. Gomez, L. Erades, K. Philippot, B. Chaudret, V. Collière, O. Balmes and J.-O. Bovin, Chem. Commun., 2001, 1474-1475.

42 D. Grandjean, R. E. Benfield, C. Nayral, A. Maisonnat and B. Chaudret, J. Phys. Chem. B, 2004, 108, 8876-8887.

43 P. T. Moseley and P. Maitlis, J. Chem. Soc. D, 1971, 982.

44 (a) P. Fau, C. Nayral, B. Chaudret and A. Maisonnat, Eur. Pat., 0947245, 1999; (b) P. Fau, C. Nayral, B. Chaudret and A. Maisonnat, US Pat., 6395053 B1, 2003.

45 N. Binsted, J. W. Campbell, S. J. Gurman and P. C. Stephenson, EXAFS Analysis Programs, Daresbury Laboratory, Warrington, 1991.

46 P. Fau, M. Sauvan, S. Trautweiler, C. Nayral, L. Erades, A. Maisonnat and B. Chaudret, Sens. Actuators, B, 2001, 78, 83-88.

47 B. Chaudret, L. Erades, P. Fau, A. Maisonnat, C. Nayral and J.-L. Simon, Int. Pat., (PCT) WO 01/02844, 2001.

48 Handbook of X-ray Photoelectron Spectroscopy, Perkin Elmer, Eden Prairie, MN, 1979.

49 C. D. Wagner, A. V. Naumkin, A. Kraut-Vass, J. W. Allison, C. J. Powell and J. Rumble, NIST Standard Reference Database 20, version 3.3, National Institute of Standards and Technology, USA, 2000.

50 J. E. Drawdy, G. B. Hoflund, S. D. Gardner, E. Yngvadottir and D. R. Schryer, SIA Surf. Interface Anal., 1990, 16, 369-374

51 D. F. Cox, G. B. Hoflund and H. A. Laitinen, Langmuir, 1985, 1, 269-273.

52 J. Kappler, N. Barsan, U. Weimar, A. Dieguez, J. L. Alay, A. Romano-Rodriguez, J. R. Morante and W. Göpel, Fresenius' J. Anal. Chem., 1998, 361, 110-114.

53 H.-J. Meyer and H. Müller-Buschbaum, Z. Naturforsch., B, 1979, 34, 1661-1662. 